\title{
Preparing teachers for HIV/AIDS education: integrated and interdisciplinary pre-service teacher education
}

\begin{abstract}
This article focuses on the views of pre-service teachers regarding an appropriate model for integrating HIV/AIDS education at a Faculty of Education. The final-year foundation and intermediate phase teachers were introduced to integrating HIV/AIDS education in Mathematics education and reflected on their four years of training. By using self-study methodology, the opinions and experiences of pre-service teachers of the two models of HIV/AIDS education in teacher preparation were explored, aiming to improve the manner in which pre-service teachers could be prepared to teach in the social and educational context of HIV/AIDS. The pre-service teachers indicated that they are under-prepared to teach in this context. Pre-service teachers were of the opinion that they could, however, be better prepared through HIV/AIDS teacher education that includes both discipline/subject and integrated models of teacher education.
\end{abstract}

Keywords: self-study; HIV/AIDS education; pre-service teachers; integrated programme

Linda van Laren, University of KwaZulu-Natal. E-mail: Vanlarenl@ukzn.ac.za.

South African Journal of Childhood Education | 2011 1(1): 95-108 | ISSN: 2223-7674 | @ UJ

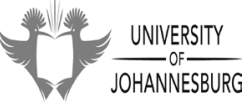




\section{Introduction}

Statistics from HIV/AIDS surveys conducted in 2008 show that approximately $10.5 \%$ of South Africans are living with HIV (Statistics South Africa, 2010). This means that close to 5.24 million (5 240 000) South Africans are required to cope with added medical, social, financial and educational burdens as a result of HIV/AIDS. Approximately 260000 of these people who are living with HIV are children below the age of 15 years, and the number of AIDS orphans (children under 18 who have lost one or both parents) in South Africa is estimated to be 1125000 (Statistics South Africa, 2010). This is the daunting context in which primary school pre-service teachers currently being prepared at higher education institutions will be required to develop and extend knowledge, skills and attitudes across the various learning areas offered in schools.

Many sound HIV/AIDS policy framework documents have been developed by the South African Department of Education (DoE) to encourage HIV/AIDS education across the higher education sector and schooling system. For example, the National policy framework for teacher education and development in South Africa (DoE, 2007: 13) notes that

[...] the debilitating effects of illness and premature death, (especially as a result of HIV and AIDS) need to be considered when teachers are being prepared, so that learners can be assisted by being provided with appropriate knowledge, skills and values.

According to the teacher education framework policy (DoE, 2007), the norms and standards for educators (DoE, 2000) are currently under revision. The current version of the DoE's norms and standards for educators (DoE, 2000) specify seven particular roles in which South African teachers are required to be competent: that of learning mediator; interpreter and designer of learning programmes and materials; leader, administrator and manager; scholar, researcher and life-long learner; community, citizenship and pastoral provider; assessor; and learning area or subject specialist.

Foundation and intermediate phase teachers (Grades R-6) can be viewed as generalists who teach across primary school subjects. As such, they are expected to facilitate learning amongst young people by fulfilling the said seven roles while many learners are coping with the effects of HIV/AIDS in their lives. More specifically, in the community, citizenship and pastoral role, practical competence of teachers in relation to HIV/AIDS are highlighted, since this is one of the areas where teachers need to be able to respond to current social and educational problems (DoE, 1999). Some of the broad areas related to HIV/AIDS that need to, for example, be discussed with primary school learners include issues of gender, poverty, discrimination and stigma. As these 'social' issues are presumably less 'sensitive' than the 'biological' issues related to HIV/ AIDS education, these topics are typically viewed as topics that may more readily be explored with young learners.

South African policy documents make provision for two options, namely a standalone subject for HIV/AIDS education and/or the integration of HIV/AIDS education in subjects/disciplines. These models suggested by the DoE for including HIV/AIDS 
education in the school or institution curriculum therefore range from what may loosely be classified as the integrated model (HIV/AIDS education integrated across the curriculum in a variety of disciplines) to what may be termed the discipline/subject model (HIV/AIDS education offered in one discipline - for example, in the South African school learning area called Life Orientation) (DoE, 1999; 2001; 2002).

After having introduced the integration of HIV/AIDS education to final-year preservice teachers registered for compulsory primary Mathematics education, I became interested in investigating the following research question:

What are foundation and intermediate phase pre-service teachers' training experiences and opinions about HIV/AIDS teacher education?

By exploring this area of interest it was possible to hear the 'voices' and opinions of pre-service teachers on appropriate models of integrating HIV/AIDS education for those being prepared to teach young learners. Furthermore, the final-year pre-service teachers' opinions could be considered as 'informed' as they had experienced close to four years at a higher education institution and were almost qualified to teach in the South African context at the time of data collection.

Since few higher education institutions had formalised policies and frameworks for HIV/AIDS education in place at the time, interventions in higher education institutions tended to be "infrequent and uncoordinated". As a result, a HIV and Teacher Education Pilot Project was initiated under the Higher Education HIV and AIDS Programme (HEAIDS, 2010) to research possible models for HIV/AIDS education at South African education faculties. Such faculties of education, where primary school teachers are trained, provide a

[...] paucity of literature on the 'how to' of curriculum integration of HIV/AIDS education (HEAIDS, 2010: vii).

The HIV and Teacher Education Pilot Project (HEAIDS, 2010) was initiated to ensure sector-wide engagement with the challenges posed by teaching and learning in an HIV/AIDS affected and infected society. The purpose of the project was to extend the personal and professional competencies of pre-service and in-service teachers through provision of support by piloting an HIV/AIDS teacher education module, and to identify, evaluate and disseminate effective strategies for inclusion of HIV/AIDSrelated education into teacher and school curricula (HEAIDS, 2010).

In the HEAIDS (2010) large-scale study a learning guide (Being a teacher in the context of HIV/AIDS) and accompanying reader formed an important part of the support provided to the 6485 pre-service and in-service teachers at South African higher education institutions who participated in the pilot study. According to the findings of the pilot study, the pilot module did not provide phase-specific practical teaching approaches to supplement material presented in the learning guide and reader, since the module was intended to provide an overview by giving a

[...] framing theory, policy, context, and information in relation of HIV/AIDS (HEAIDS, 2010: xvii). 
The module provided participants with

[...] new insights into HIV \& AIDS and a sense of empowerment through knowledge (HEAIDS, 2010: ix),

yet not with phase-specific activities that could be appropriate for young schoolgoing learners, based on the principle to not provide a handbook or specific strategies to implement in class (HEAIDS, 2010).

Two of the institution-level recommendations made by the HIV/AIDS Teacher Education Pilot Project are directed at management or heads of schools at higher education institutions, and point to the need to facilitate cross-curricular integration. This suggestion follows from the idea that HIV/AIDS education should be the responsibility of all teachers and not be narrowed to counselling or guidance teachers alone (HEAIDS, 2010).

It is clear that both the teaching and policy context offer a variety of challenges for foundation and intermediate phase teachers. However, literature on primary school pre-service teachers' expectations and opinions of integration of HIV/AIDS education in disciplines in higher education curricula is limited. Pre-service teachers who have been introduced to integration of HIV/AIDS education in a discipline such as Mathematics education have had few opportunities to voice their opinions of their experiences and expectations of such integration. Yet, to prepare pre-service teachers in the context of HIV/AIDS, it is important to take cognisance of what they consider as required to manage teaching and learning as generalists in primary schools.

This research with pre-service teachers enrolled for Mathematics education is informed by both a conceptual and a theoretical framework. The conceptual model provides an understanding of the interpretation of the particular model of 'integration' used in this study, and the theoretical framework explains which knowledge teachers require to manage teaching and learning when integrating HIV/AIDS education in Mathematics.

\section{Integrated initiatives and interdisciplinary teacher education}

\section{Integration}

A wide variety of terms are utilised in an attempt to define the concept associated with combining two disciplines such as Mathematics and HIV/AIDS education. According to Mathison and Freeman (1997: 1), the main purpose of interdisciplinary/integrated/ integrative initiatives is to assist students to

[...] synthesize discrete information and to connect such knowledge to the needs of everyday living.

By integrating Mathematics, with its particular goals, processes and learning, with HIV/ AIDS education, it is possible to connect Mathematics to the everyday experiences of many South Africans. 
Some discipline specialists are not in favour of this connected vision of an integrated curriculum, because of the blurring of the boundaries between the integrated disciplines. The integration of the Mathematics discipline with HIV/AIDS education could be interpreted by such specialists as stifling the learning of Mathematics and/ or dilution of 'high-status' Mathematics. This fear could be caused by the fact that HIV/AIDS education can be viewed as being in a privileged position due to its link to everyday living, at the expense of Mathematics learning.

The integrated approach adopted in this research, however, was a conscious bringing together of HIV/AIDS education and Mathematics, using a thematic approach where both disciplines could benefit. The primary discipline is Mathematics education, where the subject content knowledge together with the pedagogical content knowledge are bound to the Mathematics knowledge, skills and attitudes required for preparation of primary school Mathematics teachers. The theme- and inquiry-oriented activities were selected and organised by the researcher, who is a Mathematics teacher educator, to provide relevant and realistic links to the teaching context in South Africa, where social issues centred on HIV/AIDS raise critical awareness and increase understanding.

\section{Knowledge required of teachers}

To prepare Mathematics pre-service teachers and integrate HIV/AIDS education at the same time, the required knowledge, skills, attitudes and values in Mathematics education need to be extended to the benefit of both Mathematics and HIV/AIDS education. Many authors have explored areas of competence required for pre-service teachers in Mathematics teacher education. The seminal work of Manouchehri (1997) distinguishes between a range of competences that relate to Mathematics subject content knowledge, pedagogical content knowledge, and pedagogical reasoning and beliefs. In addition, the integration of HIV/AIDS education in Mathematics education requires appropriate knowledge about HIV/AIDS education. By integrating HIV/AIDS education in Mathematics, the classroom practice of teachers can be influenced by their beliefs on the teaching and learning of Mathematics as well as the novel, unfamiliar challenge of integrating HIV/AIDS education.

Manouchehri (1997: 198) states that

[...] research consistently shows that teachers translate their knowledge of Mathematics and pedagogy into practice through the filter of their beliefs.

Added to the informal, intuitive personal theories which is a product of preservice teacher's personal experiences as learners, and folk wisdom or knowledge (Mouton, 1996), pre-service teachers have their own beliefs regarding social justice and social issues. These beliefs may permeate the teaching of all disciplines that the primary school generalist teaches. This personal belief system furthermore provides a theoretical framework for classroom decision making related to sequencing of work and choice of activities. 
Because of the importance of the personal belief systems of pre-service teachers, it is necessary to take into account their opinions, suggestions and reservations on how they should be informed in pre-service teaching curricula at higher education institutions. Their experiences in pre-service training, where they are introduced to integration of HIV/AIDS education in the Mathematics discipline, allows for 'informed' reflection in relation to the research question. Using their points of view, it was possible to reflect on whether or not an integrated model and/or a discipline/subject model should be relied upon in informing pre-service teachers about them managing the teaching and learning of young learners in terms of social challenges related to HIV/AIDS education.

\section{Methodology}

\section{Self-study}

I selected self-study methodology to explore the following research question:

What are foundation and intermediate phase pre-service teachers' training experiences and opinions about HIV/AIDS teacher education?

I relied on both the interpretive and critical theoretical paradigms. On the one hand, in asking the pre-service teachers to offer, negotiate and explain their opinions (McNiff \& Whitehead, 2006) regarding integration of HIV/AIDS education in particular models (integrated and discipline/subject), I was working in the interpretive paradigm. On the other hand, when exploring my own understanding and development of practice by integrating HIV/AIDS education in Mathematics education, I relied upon a critical theoretical paradigm. As the research was used for the purpose of understanding a situation in order to change it, the study cannot be described as 'neutral', 'objective' and without differences in power relationships between the researcher and the preservice teachers.

By asking the participants to share their opinions and experiences on preparing teachers for HIV/AIDS education outside the Mathematics education lecture situation, I attempted to deal with potential biases in being both researcher and Mathematics education lecturer. Furthermore, the responses of the participants were not used within the Mathematics education context for assessment purposes. The participants were given the opportunity to decide whether or not they were willing to take part in this research, which included reflection on the practice of their Mathematics education lecturer.

According to Loughran (2004), self-study methodology defines the focus of a study and not the way the study is carried out, allowing for the use of multiple methods. In addition, self-study implies the study of a researcher's actions and ideas, as well as of others involved in the research (Hamilton \& Pinnegar, 1998). In researching my reflective practice as a phenomenon through systematic documentation of the methods that I have been using in the lecture hall, I was able to combine my practice 
as a Mathematics teacher educator with my experiences and theories (Griffiths, 2003) about the integration of HIV/AIDS education using a thematic approach to integrated classroom activities. I concur with Griffiths (2003: 55), who states that

Social justice is a verb.

As a Mathematics teacher educator I took action and "did something" for social change by integrating HIV/AIDS education in primary Mathematics education modules.

Although self-study may be criticised in terms of validity and reliability, these concepts are strongly linked to research in the technical (empirical) paradigm, where generalisability of results are sought. In this study, which relied on a qualitative approach, it was more appropriate to strive towards trustworthiness of findings. Feldman (2003) notes that trustworthiness may be achieved in self-study through providing clear and detailed descriptions of how data have been collected and analysed.

\section{Research design, data selection and analysis}

The research site was at my own higher education institution where I am a Mathematics teacher educator. This work is an extension of research conducted by means of a focus group with seven final-year pre-service teachers, who volunteered to collaborate with me to design activities to initiate the integration of HIV/AIDS education in Mathematics (Van Laren, 2007). To extend this research, an entire group of 101 Bachelor of Education pre-service teachers who were registered for a compulsory final-year primary Mathematics education module were introduced to including thematic activities with HIV/AIDS education in Mathematics.

I provided the pre-service teachers with a handout on possible integration activities that may be used in a Mathematics classroom (Van Laren, 2009). The activities in the handout were developed in collaboration with the focus group consisting of preservice teachers who had been teaching integrated Mathematics lessons during their foundation phase and intermediate phase classroom teaching practice sessions. The integrated activities were designed to meet with the requirements of the Grade 3/4 Mathematics and Life Orientation learning outcomes presented in the National Curriculum Statement (DoE, 2002).

I selected 11 of the 101 pre-service teachers, who had been introduced to integration of HIV/AIDS education in the Mathematics education module, to discuss their opinions about the integrated and discipline/subject models and their experiences of HIV/ AIDS teacher education preparation. These pre-service teachers were selected on the basis of them preparing interesting, unique, metaphorical drawings to illustrate how integration of HIV/AIDS education in Mathematics may occur (Van Laren, 2007). Even though the introductory drawing activity was not considered to be part of the research, I selected the 11 pre-service teachers on the basis of these drawings. Only eight of the 11 selected pre-service teachers made an appointment with me to share their opinions/experiences in HIV/AIDS education preparation at the relevant faculty of education over the four years of their studies. Six of these pre-service teachers were 
registered as foundation and intermediate phase pre-service teachers. These six preservice teachers became participants in this research study.

The pre-service teachers were asked for written permission to use their responses, and were also asked to discuss and complete open questions on a questionnaire that focused on exploring potential models for integrating HIV/AIDS education at our Faculty of Education. I used the following pseudonyms for the participants: Denise, May, Lisa, Celeste, Felicity and Anisha.

The participants were asked to respond and explain their responses to the following questions:

1. Do you think that pre-service teachers should be informed by discipline specialists in Life Orientation or gender education on how to manage the teaching and learning of HIV/AIDS education at the classroom and school level?

2. Have you been informed by discipline specialists in Life Orientation or gender education on how to manage teaching and learning of HIV/AIDS education at the classroom and school level?

3. Do you think that pre-service teachers should be informed by discipline specialists across disciplines (Mathematics, Science, etc.) on how to manage the teaching and learning of HIV/AIDS education at the classroom and school level?

4. Have you been informed by discipline specialists (Mathematics, Science, etc.) on how to manage teaching and learning of HIV/AIDS education at the classroom and school level?

5. In your opinion, how could Mathematics education modules assist with the development of knowledge, skills or attitudes in HIV/AIDS teacher education?

The responses of the six pre-service teachers to the five questions were transcribed and tabulated to facilitate analysis. The analysis of the opinions of the participants was achieved by looking for trends in the responses to each question, and by linking their responses to the module electives of each participant in an attempt to understand their experiences of HIV/AIDS education preparation at our higher education institution.

The first question explores the opinions of the pre-service teachers on being informed by Life Orientation or gender education specialists. In other words, do they consider it important to be informed by discipline/subject specialists in one discipline on how to manage teaching and learning about HIV/AIDS education. All six pre-service teachers were of the opinion that this was necessary in their teacher preparation. The responses of four participants made mention of the fact that HIV/AIDS is related to everyone's lives and that it is particularly important for teachers to be informed about it. For example, May wrote:

Yes, we will very likely be confronted by these issues in a classroom (especially with AIDS being so relevant in South Africa).

Furthermore, Lisa and Celeste considered it necessary to have compulsory core modules by discipline/subject specialists to inform all pre-service teachers on teaching this social phenomenon. 
The second question required information regarding the participants' experiences in terms of being prepared to provide HIV/AIDS education by discipline/subject specialists in one discipline at our higher education institution. Of the six pre-service teachers, only Anisha elected to take Life Orientation as a major subject. Her response was

Yes, HIV and AIDS have been integrated into Life Orientation.

The other five participants had received no information on managing the teaching and learning of HIV/AIDS education through discipline/subject specialists. Felicity pointed out that the core Life Orientation module offered to all the pre-service teachers made

[...] very slight reference to HIV/AIDS, but not nearly enough in the four years I have been here. Otherwise, absolutely no module has specifically allocated teaching time towards educating us regarding HIV/AIDS!

The third question asked the pre-service teachers if they considered it necessary to be informed about managing the teaching and learning of HIV/AIDS education by discipline specialists across the curriculum (in other words, using an integrated model). Only Celeste was not in favour of this model:

There should be a general module on HIV/AIDS education that shows us how to incorporate it across learning areas, as a lot of us are generalists.

However, Denise considered the integration model as suitable because

[...] HIV and AIDS education can be integrated into all disciplines, educators just need to know how to do so.

Felicity was in favour of being informed across disciplines, but cautioned against too much integration that may cause "HIV \& AIDS education fatigue". She wrote:

Yes, because the same children attend all of those subjects, so the teacher needs to be prepared, sensitive and well equipped. However, there must not be an over 'forcing' of the learners to be constantly overwhelmed by HIV/AIDS integration as not every subject has to be integrated, only where necessary.

The fourth question asked about participants' preparation experiences in HIV/AIDS education by specialists across disciplines at our higher education institution. All six participants indicated that there was brief coverage in Mathematics education, and referred to the Mathematics education module that I taught in their final year. Lisa suggested that integration of HIV/AIDS education should be considered in all disciplines and "especially method modules", where teaching and learning of pedagogical content knowledge and pedagogical reasoning of disciplines is considered. May felt that further training of pre-service teachers is necessary, and that

\section{[...] we could definitely have used more within our four years of training.}

The last question requested reflection on how Mathematics education modules could assist in the HIV/AIDS education preparation of pre-service teachers. The opinions of the pre-service teachers assisted me with my own reflections on how I could improve on delivering integrated Mathematics education modules. All six participants provided positive comments on how integration of HIV/AIDS education in Mathematics education modules could benefit teacher preparation. Denise commented on the fact that: 
Mathematics could help to develop learners' awareness and knowledge on HIV and AIDS, ways to deal with it and what type of attitude to have towards HIV and AIDS and people living with it.

May pointed out that the Mathematics education modules could

[...] show future teachers how easily HIV/AIDS can be integrated into other subjects/ learning areas as well.

Anisha found that

[...] useful ways that are practical to integrate HIV/AIDS [...]

can be introduced through Mathematics education. According to Celeste, HIV/ AIDS education can be brought into Mathematics lessons using real-life situations in a 'subtle' manner. Lisa observed that both HIV/AIDS education and Mathematics can benefit through integration, but she felt that additional emphasis and

[...] a stronger focus would be more beneficial.

Felicity considered that further information on

[...] examples of successful incidents where attitudes can be improved [...]

together with feedback on first-hand experiences would benefit integrated Mathematics education modules.

\section{Discussion}

Many South African teenagers and adults are of the opinion that they are over-exposed to HIV/AIDS. This 'fatigue' of HIV/AIDS results in a so-called "sick of AIDS" (Mitchell \& Smith, 2003) attitude towards information about the pandemic. As school-going learners usually consider HIV/AIDS in the learning area Life Orientation, Mathematics education is not typically utilised to integrate social issues in HIV/AIDS and engage with teaching and learning about HIV/AIDS. It was thus necessary to give the selected preservice teacher participants an opportunity to express their opinions on the manner in which HIV/AIDS education should be approached in their training.

From the pre-service teachers' responses it is clear that they would welcome specific information on managing the teaching and learning of HIV/AIDS education during their training at a higher education institution. The pre-service teachers require phase-specific guidelines about ways to consider this sensitive topic in classrooms.

From the responses of the participants it is also clear that they were not included in the large-scale study conducted in 2007 and 2008 (HEAIDS, 2010), where personal and professional competences were provided through the HIV/AIDS Teacher Education Pilot Project. However, the participants were of the opinion that they required more than personal and professional competences in being HIV aware, HIV competent, and HIV safe. Only Anisha, who elected to take Life Orientation as a major subject, had reportedly been prepared to manage teaching and learning of HIV/AIDS education at classroom level. None of the other generalist foundation and intermediate phase preservice teachers was given this training opportunity. Yet, all participants were of the opinion that the information should be provided through a discipline/subject model. 
Only Celeste was in favour of being informed on managing the teaching and learning of HIV/AIDS education through an exclusively discipline/subject model. The other participants' responses indicated that the discipline/subject model should be supplemented with information provided by discipline specialists across disciplines in an integrated model. It is significant that Anisha was also of the opinion that both models should be provided for pre-service education, since she observed that

[...] all disciplines contain principles that are useful and of importance that can be used.

During their four years of teacher education, however, the participants were only provided with possible strategies to integrate HIV/AIDS education briefly in the Mathematics education module that I taught. Felicity expressed her concern about HIV/AIDS fatigue by emphasising that the links between HIV/AIDS education should be carefully considered and orchestrated so that the integrated model is only implemented where appropriate.

All the responses of the participants indicate that their attitudes towards teaching and learning about HIV/AIDS education were appropriate, and that they would welcome assistance in managing HIV/AIDS education in the classroom situation. Even after focusing on integration of HIV/AIDS education in a Mathematics education module for approximately one-twelfth of the module, the participants were able to provide insightful reflections regarding the needs of prospective learners in their trust and regarding their under-preparedness to teach young learners in the South African HIV/AIDS context.

\section{Conclusions and implications}

The outcomes that were identified in the HEAIDS module and learning guide were developed from three inter-related perspectives - socio-ecology, inclusive education and health promotion (HEAIDS, 2010). However, the HEAIDS (2010) report emphasised that these perspectives in a stand-alone module would need to be supplemented with work in school-based teacher education programmes. This is precisely what the participants in this research are calling for in HIV/AIDS education preparation.

This research shown that, to attend to attitudinal change of pre-service teachers that would influence behavioural change, generalist teachers would benefit from being informed by discipline specialists, where age-appropriate activities and ideas are provided that are guided by the school curriculum. This discipline-specific information on appropriate strategies for integration should be included in teacher preparation modules where pedagogical content knowledge and pedagogical reasoning are explored in methods of teaching and learning such as Mathematics education. Some topics which relate directly to sexuality need to be explored with older learners, but younger learners can be engaged with less sensitive topics such as stigma, discrimination and living positively using authentic, age-appropriate activities. If foundation and intermediate phase pre-service teachers are given pedagogic know-how to broach 
these issues from a variety of discipline specialists' perspectives, then these pre-service teachers are more likely to take up the strategies in their own future classrooms.

If, in addition to the discipline/subject model, the integrated model is implemented for pre-service teacher preparation at higher education institutions, then the onus would not be on one discipline to consider the complex issues related to HIV/AIDS education. The completion of the one module in a discipline/subject model could result in a so-called "done and dusted" approach where the pervasiveness of HIV/AIDS would be ignored. It is important to make all pre-service teachers HIV aware, HIV competent and HIV safe through general personal and professional empowerment. In addition, pre-service teachers - particularly generalist teachers - require further assistance that could be gained through specialist advice from a variety of discipline specialists through an integrated model.

The use of real-life contexts such as HIV/AIDS in the teaching and learning of a topic should not be seen as a threat to the discipline/subject. Lesh's (1979) seminal education research on the modeling of concepts showed that learners benefit from being given a variety of ways to think about, discuss and test new ideas while solving problems. In other words, learners benefit from working with multiple representations of a concept that includes real-life applications. Furthermore, as discipline specialists, teacher educators who adopt the integrated model can rely on their own teaching experiences and theories to devise appropriate integration strategies to benefit both their discipline and HIV/AIDS education, since a variety of interpretations and levels of integration are possible.

Including HIV/AIDS education is also a way of addressing values of social justice in practice through taking action (Griffiths, 2003). The action that I took by integrating HIV/AIDS education in Mathematics education in teacher preparation was seemingly "intelligent, responsive and rational" (Griffiths, 2003: 114) and coherent with most of my other actions as a Mathematics teacher educator. Furthermore, I now understand the context in which pre-service teachers will be required to teach and want to do something about better equipping pre-service teachers to learn about and prepare Mathematics lessons that take cognisance of the HIV/AIDS pandemic.

\section{References}

Department of Education. (1999). National policy on HIV/AIDS for learners and educators in public schools, and students and educators in further education and training institutions. Government Gazette, 410(20372).

Department of Education. (2000). Norms and standards for educators. Government Gazette, 415(20844).

Department of Education. (2001). Education White Paper 6. Special needs education: Building an inclusive education and training system (EWP6). Pretoria: DoE. 
Department of Education. (2002). Revised national curriculum statement, Grades R-9 (Schools): Mathematics. Pretoria: DoE.

Department of Education. (2007). National policy framework for teacher education and development in South Africa (NFTE). Government Gazette, 502(29832).

Feldman, A. (2003). Validity and quality in self-study. Educational Researcher, 32(3): 26-28. Griffiths, M. (2003). Action for social justice in education: Fairly different. Maidenhead: Open University Press.

Hamilton, M. L. \& Pinnegar, S. (1998). Introduction: Reconceptualizing teaching practices. In: M. L. Hamilton (ed.), Reconceptualizing teaching practice: Self-study in teacher education. London, UK: Falmer Press.

Higher Education HIV and AIDS (HEAIDS) Programme. (2010). HIV and AIDS in teacher education - Evaluation report of a pilot project in South African higher education institutions. Pretoria: Higher Education South Africa.

Lesh, R. (1979). Mathematical learning disabilities. In: R. Lesh, D. Mierkiewicz \& M. G. Kantowski (eds.), Applied mathematical problem solving. Columbus, OH: ERIC/SMEAC.

Loughran, J. J. (2004). A history and context of self-study of teaching and teacher education practices. In: J. J. Loughran, M. L. Hamilton, V. K. LaBoskey \& T. Russell (eds.), International handbook of self-study of teaching and teacher education practices. Dordrecht, The Netherlands: Kluwer Academic.

Manouchehri, A. (1997). School mathematics reform: implications for mathematics teacher preparation. Journal of Teacher Education, 48(3): 197-209.

Mathison, S. \& Freeman, M. (1997). The logic of interdisciplinary studies. Paper presented at the 1997 Annual Meeting of the American Educational Research Association, Chicago. [Online]. Available at: http://cela.albany.edu/reports/mathisonlogic12004.pdf. Accessed: 4 June 2008.

McNiff, J. \& Whitehead, J. (2006). All you need to know about action research. London: Sage.

Mitchell, C. \& Smith, A. (2003). 'Sick of AIDS': life, literacy and South African youth. Culture, Health \& Sexuality, 5: 513-522.

Mouton, J. (1996). Understanding social research. Pretoria: Van Schaik.

Statistics South Africa. (2010). Statistical release P0302: Mid-year population estimates, 2010. [Online]. Available at: http://www.statssa.gov.za/publications/P0302/P03022010. pdf. Accessed: 28_October 2010.

Van Laren, L. (2007). Using metaphors for integrating HIV and AIDS education in a mathematics curriculum in pre-service teacher education: an exploratory classroom study. International Journal of Inclusive Education, 11(4): 461-481. 
Van Laren, L. (2009). Integrating HIV \& AIDS across the curriculum. In: C. Mitchell \& K. Pithouse (eds.), Teaching and HIV \& AIDS. Northlands: Macmillan South Africa. 